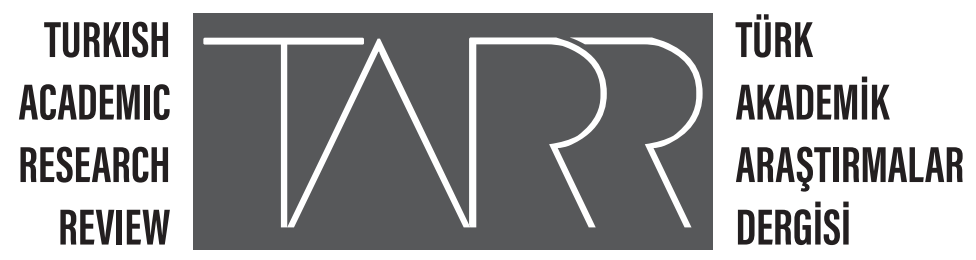

\title{
Ölüme Uyanmak: Yaşayanların Dilinden Ölüm Eşiği Deneyimleri
}

Waking to Death: Near-Death Experiences in The Context of Psychology of Religion

\section{Figen Sargin - Orhan Gürsu}

Yüksek lisans Öğrencisi, Akdeniz Üniversitesi İlahiyat Fakültesi, Din Psikolojisi ABD, figensargin@gmail.com Orcid: 0000-0002-5875-197X

Doç. Dr. (Sorumlu Yazar), Akdeniz Üniversitesi, İlahiyat Fakültesi, Din Psikolojisi ABD

orhangursu@akdeniz.edu.tr

Orcid: orcid: 0000-0002-7478-371X

\author{
Makale Bilgisi | Article Information \\ Makale Türü-Article Type | Kitap İncelemesi / Book Review \\ Geliş Tarihi-Date Received | 14 Mayıs / May 2020 \\ Kabul Tarihi-Date Accepted | 25 Haziran/June 2020 \\ Yayın Tarihi-Date Published | 30 Haziran / June 2020 \\ Yayın Sezonu | Nisan-Mayıs-Haziran \\ Pub Date Season | April-May-June
}

Atıf/Cite as: Sargın, Figen-Gürsu Orhan, Ölüme Uyanmak: Yaşayanların Dilinden Ölüm Eşiği Deneyimleri/Waking to Death: Near-Death Experiences in The Context of Psychology of Religion, Saliha Uysal, İstanbul, 2019, Marmara Akademi Yayınları No:7 Birinci Basım, 295 s, ISBN:978-605-6730-6-3.tarr: Turkish Academic Research Review, 5 (2), 319-324 doi: tarr.737206

İtihal/Plagiarism: Bu makale, en az iki hakem tarafından incelenmiş ve intihal içermediği teyit edilmiştir. / This article has been reviewed by at least two referees and confirmed to include no plagiarism. https://dergipark.org.tr/tr/pub/tarr

Copyright (C) Published by Mehmet ŞAHİN Since 2016- Akdeniz University, Faculty of Theology, Antalya, 07058 Turkey. All rights reserved. 


\section{Ölüme Uyanmak: Yașayanların Dilinden Ölüm Eșiği Deneyimleri Waking to Death: Near-Death Experiences in The Context of Psychology of Religion}

\section{Figen Sargın ${ }^{1}$ - Orhan Gürsu ${ }^{2}$}

Saliha Uysal

İstanbul, 2019, Marmara Akademi Yayınları No:7 Birinci Basım, 295 s, ISBN:978-605-6730-6-3

"Her nefis ölümü tadacaktır" ${ }^{3 "}$ ayetiyle bildirildiği üzere ölüm, insanın kaçınılmaz sonudur; hadis kaynaklarında "lezzetleri yok eden" "diye tasvir edilen ve çokça hatırlamamız gerektiği söylenen bir gerçektir. Yahya Kemal Beyatlı 'Sessiz Gemi' şiirinde ölümü, "her biri memnun ki yerinden, dönen yok seferinden” diyerek anlatır. Uysal'ın kitabına konu olan ölüm eşiği deneyimi (ÖED), gidenlerin geri geldiği bir deneyimdir.

Greyson (2006), ölüm eşiği deneyimi tabirinin İngilizce olarak near death experince şeklinde, ilk kez bir psikiyatr olan Raymond Moody tarafindan 1975'de kullanıldığını söylemiştir. Uysal'ın da bir dipnotta belirttiği üzere, bu terimin çok daha önce Fransız psikolog Victor Egger tarafindan expérience de mort imminente olarak kullanıldığı görülmektedir (s.94). Uysal'ın gözünden kaçmamış olan terimin ilk kullanıma dair bu detay, araştırmanın itinalı yapılmış olduğunu göstermektedir.

Ölüm eşiği deneyimi Türkçe kaynaklarda genellikle ölüme yakın deneyimler veya yakın ölüm deneyimleri olarak kullanılmaktadır. Öbür dünyaya yolculuk, benlik sahasından ayrılma, ölüme yakın vizyonlar gibi değişik adlarla da anılan Ölüm Eşiği Deneyimini Uysal, (2007) şöyle tanımlamaktadır:

ÖED, kalp krizi, doğum, trafik kazası, diğer kazalar gibi nedenlerle klinik olarak ölü kabul edilen insanların ruhlarının fiziksel bedenlerini terk etmesi üzerine farklı bir mekâna veya âleme gittikleri; bedenlerinin dışında kendilerini yahut etrafinda olanları izledikleri; hatta bedenlerine geri döndükten sonra bedenleri dışındayken izledikleri şeyleri detaylarıyla aktardıkları; yoğun sevgi, buzur, ışık, vefat eden yakınlar gibi fenomenleri algıladıkları deneyimlerdir (s.93).

1 Yüksek lisans Öğrencisi, Akdeniz Üniversitesi İlahiyat Fakültesi, Din Psikolojisi ABD, figensargin@gmail.com, ORCID. 0000-0002-5875-197X

2 Doç. Dr. (Sorumlu Yazar). Akdeniz Üniversitesi, İlahiyat Fakültesi, Din Psikolojisi ABD, orhangursu@akdeniz.edu. tr, orcid: 0000-0002-7478-371X

3 Ali İmran, 3/185

4 Nesai, Cenaiz, 3 
Daha önce Din Psikolojisi bağlamında çalışılmamış olan ölüm eşiği deneyimi, ilk defa Uysal'ın bu çalışmasıyla Türkiye'deki literatüre kazandırılmış olması bakımından önemlidir. Yazar, giriş bölümünde, çalışmanın önemini şöyle ifade etmiştir:

Gerek psikoloji alanında, gerekse din psikolojisi alanında ölüm ve din, ölüm ve ölüm ötesi, ölüm psikolojisi, ölüm korkusu, ölüm kaygısı ve dindarlık, ölüm ilgileri gibi ölümle alakalı birçok konuda çeşitli araştırmalar yapılmasına rağmen, ÖED üzerine odaklanmış özel bir çalıșma bulunmamaktadır. Bu da araștırmayı literatüre katkı să̆laması açısından önemli ve anlamlı kılmaktadır. Araştırmanın iki açıdan önemi bulunmaktadır. Birincisi araştırmanın insanları dini, sosyal ve psikolojik açıdan meşgul eden önemli bir probleme temas etmesi, ikincisi ise din psikolojisi literatüründe belli bir boșluğu doldurma misyonu.

Uysal, Ölüme Uyanmak adlı bu çalı̧̧masıyla İstanbul Üniversitesinde yapmış olduğu doktora tezini kitaplaştırmıştır. Kitap, doktora tezi olduğu için akademik çevreye hitap eder bir formatta hazırlanmıştır. Yazar, halen İstanbul Üniversitesinde araştırma görevlisi olarak vazifesine devam etmektedir. İngilizce ve Arapça lisans programlarından mezun olduğu için, bu dillerin kendisine sağladığı avantajı kullanarak hem batıdaki hem de doğudaki eserlerden edindiği bilgileri okurun istifadesine sunmaktadır.

Uysal, kitabın amacını giriş bölümünde şöyle ifade etmektedir:

"ölüm eşiği deneyimi yaşayan bireylerin deneyimlerinin ve deneyim sonrası hayatlarının dini, manevi ve psikolojik açılardan nasıl etkilendiğinin ortaya çıkarılmasıdır. Bu araştırma, ayrıca, ölüm eşiği deneyimi yaşayan müslüman kişilerin deneyimleri üzerine odaklanmakla beraber onların deneyimleri ile farklı inanç mensuplarının deneyimleri ve deneyimlerinden sonraki hayatlarına etkileri karşılaștır1 maktadır. Aynı zamanda bu çalışma, ölüm eşiği deneyimlerinin ne olduğuna dair bilgi toplamak maksadıyla da yapılmıştır.

Kitap, giriş bölümünden sonra kavramsal çerçeve, yöntem ve bulgular olmak üzere üç ana bölüm ve sonuçtan oluşur. Giriş bölümünde Uysal, konunun ilgi duyduğu bir alan ve kendisinin de yaşadığı bir deneyim olduğu için seçildiğinden bahsetmektedir. Ayrıca, konunun daha çok batı kaynaklarından istifade edilerek araştırıldığından da söz etmektedir. Yazar, giriş bölümünü, konunun önemi, literatüre katkısı, yöntemi ve sınırlılıklarından bahsederek içeriğin kısa bir özetiyle sonlandırmaktadır ${ }^{5}$.

"Anlatı araștırmaları (narrative studies), insanların bir konuya veya duruma ilişkin deneyimlerini yaşamış oldukları bikayeler ile inceler. İnsanların yaşadıkları olayların ardışık olarak düzenlenmesi, bu olaylar arası ilişkilerin kurulması ve böylece bu olayların belli hedef kitle için anlamlandırılması sağlanır." (Büyüköztürk, K1lı̧ Çakmak, Akgün, Karadeniz\& Demirel, 2008/2017)

5 Kitap Tanıtımı için bkz. Ömer Faruk Teber, “Kitap Tanıtımı”, Dini Araştırmalar, C.2, S.6 Ocak-Nisan 2000, s239-242. 
Uysal'ın çalışması da betimsel bir anlatı araştırması olması nedeniyle kişilerin ölüm eşiği deneyimlerinin nasıl gerçekleştiğini incelemektedir. Bu deneyim esnasında yaşanan olaylar ardışık bir düzende, aralarında ilişki kurularak anlatılmaktadır. Bulgular kavramsal çerçevede kapsamlı literatür taramasından sonra sunulan olguların doğruluğunu ispatlar mahiyettedir. Giriş bölümünde Uysal çalışmasının amacının tam olarak bu olduğundan bahsetmektedir.

Yazar kavramsal çerçeveye "ruh-beden ilişkisi” ile başlamıştır. Kavramsal çerçevenin, günümüz teknoloji dünyasında, bilginin bir tık uzakta olduğu bir zamanda bu kadar uzun tutulması eleştirilebilir. Uysal, biraz da kavramsal çerçevenin uzunluğunu savunur mahiyetteki gerekçesini şöyle dile getirmektedir: "Ölümün adeta unutulduğu, ölüm ve ötesiyle ilgili kavramların konuşulmasının tabu haline getirildiği günümüzde böylesi bir konuyu çalışırken, bu durumun olumsuz etkilerini ortadan kaldırmanın bir yolu, güçlü bir kavramsal çerçeve oluşturmaya bağlıdır” (s.21). Ruh-beden ilişkisi bağlamında ruhun Arapça, Yunanca, Latince, Fransızca, İngilizce, Almanca ve hatta Sanskritçe'deki manasının verilmesi ölüm eşiği deneyimini açıklamaya yardımcı olmaktan çok Uysal'ın tezinin bir amacı olan bilgilendirme misyonuna hizmet eder mahiyettedir.

İkinci bölümde “ölüm” kavramı ele alınmış ve farklı düşünce sistemlerinde ölümün nasıl alg1landığı ve tanımı açıklanmıştır. Sonrasında geçmişten günümüze ölüm olgusu başlığ 1 ile ölümün, mit ve destanlarda, batı düşüncesinde, İslam düşüncesinde, diğer dini geleneklerde ve modern psikolojide nasıl anlaşıldığ incelenmiştir. Bu bölümde ölüm hakkında söylenmiş aforizmalara yer verilmiştir. Örneğin; felsefeyi "ölümden korkmamayı ögreten bir bilgi alanı" olarak gören Montaigne'e göre felsefe yapmak, "ölmeyi öğrenmektir”. İnsanı bütün dertlerin bittiği yere götürmesi sebebiyle ölüm için dertlenmeyi "budalalık” olarak niteleyen Montaigne, "ölüm, başka bir hayatın kaynağıdır" der.

Kavramsal çerçevenin son ve en önemli kısmını oluşturan "ölüm eşiği deneyimi” bölümü de ÖED olgusunun tanımı ile başlamaktadır. Tarihi süreçte Tibetlilerin Ölüler Kitabı denilen Bardo Thodol ile başlayan bölüm Antik çağda Platon'un ÖED mahiyetindeki ER hikâyesiyle devam etmektedir (s.96). Yazar, tarihi süreci günümüze kadar dünyanın değişik yerlerinden farklı dönemlerde gerçekleşen olaylar eşliğinde sunmuştur. Bu bölümün bir sonraki başlı̆̆ını ÖED karakteristikleri oluşturmaktadır. Bu bölüm de ÖED öncesi, esnası ve sonrası olmak üzere üç ana bölüme ayrılarak oldukça detaylı bir şekilde ele alınmıştır.

Daha sonra bulgular kısmına destek sağlayacak olan ÖED yaşayanların deneyim öncesi demografik özellikleri, kişilik yapıları, ilaç ya da madde kullanım durumları, deneyim öncesi ÖED hakkında bilgi sahibi olma durumları, ruhsal ve inanç durumları da ele alınmıştır. ÖED esnasında tecrübe edilen durumlar; bedenden ayrılma, boşluk, 1şık, tünel, kutsal varlık ve refakatçilerle karşılaşma, sevgi, mutluluk, huzur ve yüce bilgiye ulaşma, sesler, hayatı gözden geçirme ve geri dönmede isteksizlik olarak sıralanmıştır. Teorik bir çerçevede işlenen bu başlıklar bulgular bölümünde de aynı şekilde sunulmuştur.

Uysal son olarak da, ÖED sonrası karakteristiklerden bahsetmektedir. ÖED’lere yönelik nedensel iddialar ve cevaplar kısmında konuya dair teori ve hipotezlerden bahsederek: "Bilim insanları, bu deneyimlerin çıkış noktasını kabullenmekte zorluk 
çekmektedirler. Bu yüzden bilimsel olarak açıklamak amacıyla, birçok kuram öne sürülmüşüur." sözleriyle konuya giriş yapmıştır. Bu kuramları tek tek ele almış ve hipotezleri çürütmek için yazılan makaleleri de beraberinde sunmuştur. Konuya dair sonucu şöyle dile getirmiştir: "günümüzde nörobilim hâlâ ÖED'lerde doğruluğu ispatlanmış beden dışı fenomeni güvenilir bir fiziksel açıklamayla izah edebilmiş değildir. Bu tarz açıklamaların bu izahı hiçbir zaman yapamayacağına inanılmaktadır” (s.176). Ancak her geçen gün ilerleyen teknolojik gelişmelerin zaman içinde fiziksel bir açıklama sunabilme ihtimalinin de göz ardı edilmemesi gerektiği düşünülebilir.

Yazar, kavramsal çerçeve içinde Analitik Psikolojinin kurucusu olan C.G. Jung (s.108), Rahibe Azize Terasa (s.106) ve tanınmış diğer pek çok kişinin (s.100), ölüm eşiği deneyimi yaşadığından bahsetmektedir (s.108). Bu örneklerle Uysal'ın, konunun ne kadar yaygın olduğunu göstererek bir farkındalık yarattığı düşünülmektedir.

Özetle, ruh, beden, ölüm ve ÖED kavramlarına dair veriler batıdan edinilen bilgiler ışı̆̆ında düzenli bir şekilde derlenmiştir. Bu kavramların tarihi süreçteki kullanımlarına da yer verilmiştir. Ölüm eşiği deneyimi ve onu yaşayanların temel karakteristikleri farklı aşamalarda açık ve net bir şekilde açıklanmıştır. Ölüm eşiği deneyiminin din psikolojisi ve mistik deneyim ile ilişkisine değinilerek kavramsal çerçeveye son verilmiştir.

İkinci bölümde yöntem başlı̆̆1 altında çalışmanın tipi, veri toplama amacı, çalışma grubu ve çalışmaya dair zorluklar, imkânlar ve sınırlılıklar açıklanmıştır. Ulaşılmak istenen amaca yönelik yöntem seçimi gerekçelendirilmiştir. Bu çalışma nitel bir çalışmadır ve çalışma grubu 13 kişiden oluşmaktadır.

Gay ve meslektaşlarının (Gay'dan aktaran Büyüköztürk 2017) 'Educational Research' kitabında belirttiği üzere "Var olan sınırlılıkların dürüstçe ve açık bir şekilde araştırma raporunda belirtilmesi gerekir” ki; bu bağlamda Uysal, çalışmasının sınırlılıklarını 'Yöntem' bölümünde şöyle dile getirmiştir:

Çalı̧̧ma grubu 'amaçlı örnekleme' yöntemiyle belirlenmiştir. Bu yöntem, birden fazla örnekleme tipini içermesi sebebiyle tercih edilmiştir. Çalışma nitel bir araştırma olması nedeniyle küçük bir çalışma grubu üzerinde gerçekleştirilmiştir. Çalışma grubunun büyüklüğü yerine, çalışma grubunun araştırmanın gereksinim duyduğu bilgiyi sağlamasına dikkat edilmiştir. Bu çerçevede temel amaç, katılımcılara benzer ya da aynı özellikleri gösteren ÖED yaşamış diğer kişilere genelleme yapılabilmesidir. Literatürde nitel araştırmalar için çalışma kapsamına alınacak kişi sayısının kesin olarak belirtilmemesi, dolayısıyla bu araştırmada istenilen doygunluğa, başka bir ifadeyle verinin kendisini tekrarladığı noktaya gelindiğinde çalısma tamamlanmıştır (s.191).

Yazar ayrıca, "konunun az rastlanır oluşu ve ÖED yaşayan Müslüman bireylerin deneyimlerini paylaşmaya pek açık olmamaları nedeniyle çalışma grubu 13 kişi ile sınırlı kalmıştır” diyerek örneklem küçüklüğünü gerekçelendirmiştir (s. 192). Ancak Uysal kitabında, diğer din mensuplarının deneyimlerini severek anlattıklarını bildirmektedir (s. 236). Uysal'ı onaylar mahi- 
yette, Caroline Myss de, Kenneth Ring'in bir kitabına yazdığı önsözde, ÖED yaşayanların deneyimlerini anlatmaya çok istekli olduklarını söylemiştir (Ring, 2006). Müslüman olmayanlar arasında ÖED deneyimi yaşamış kişilere ulaşmanın kolaylığı hakkında Ring de ÖED ile ilgili yaptığı derslerde, her sınıfta bu deneyimi yaşamış birinin varlığından bahsetmektedir (Ring 2006). Greyson (1983) da The Near-Death Experience Scale Construction, Reliability, and Validity adlı makalesinde "8 milyon Amerikalı bu deneyimi yaşamıştır" diyerek bu deneyimi yaşayanların çokluğundan bahsetmektedir. Müslümanların deneyimlerini anlatmak istememeleri araştırma konusu olarak başka bir çalışmada incelenebilir.

Üçüncü bölümde bulgular, tezin ana temasını oluşturmaktadır. Bu bölüm de kavramsal çerçeve gibi, ölüm eşiği deneyimi öncesi, esnası ve sonrası bulgular şeklinde üç başlık altında incelenmiştir. Bu bölümde, kavramsal çerçevede batıdan aktarılan araştırmalarda görülen sonuçların Türkiye'de Uysal'ın yaptığı çalışmayla örtüştüğü görülmektedir. Örneğin; Kavramsal çerçeve bölümünde yazar, "ÖED yaşayan bir çok kişi, bu alem ile öte alem arasında - tünel olarak adlandırılan - bir tür geçiş dönemi tecrübe eder” (s.140) şeklinde bir ifadeye yer verir ve sonraki sayfada "ÖED yaşayan yabancı katılımcıların büyük bir kısmı "tünel”den geçtiklerini anlatmaktadır" der. Daha sonra çalışmasının bulgular kısmında, "katılımcıların 3’ünde tünel unsuruna rastlanmıştır.” Ífadesini kullanır (s.220).

Sonuç bölümünde bulgular özet olarak tekrar edilerek 'din psikolojisi bağlamında ölüm eşiği deneyimine dair sonuçlar ve öneriler okuyucunun bilgisine sunulmuştur.

"Bir musibet bin nasihatten iyidir" sözünün ispatı mahiyetinde olan bu araştırmanın bulguları, ölüm eşiği deneyimlerin, bu deneyimleri yaşayan insanların hayatlarında derin dini ve psikolojik değişikliklere yol açtığını göstermektedir. Herkesin bu deneyimi yaşaması mümkün olmasa da bu kitap vasıtasıyla, bu deneyimi yaşamış olanların hikâyelerine ulaşmak mümkündür. Son olarak; bazı uzun cümleler anlamayı zorlaştırabilir ama genel olarak kitap, Uysal'ın konuyu net bir şekilde açıklaması ile herkes tarafından anlaşılır hale getirilmiştir.

\section{Kaynakça}

Büyüköztürk, Ş., Kılıç Çakmak, E., Akgün, Ö.E., Karadeniz, Ş.\& Demirel, F. (2017). Bilimsel Araştırma Yöntemleri. Pegem Akademi.

Görmez, M. vd., (2014). Hadislerle İslam. Diyanet İşleri Başkanlığı. Cilt 7, s.545-547.

Greyson, B. (1983). The Near-Death Experience Scale Construction, Reliability, and Validity. The Journal of Nervous and Mental Disease: 171, 369.

Greyson, B. (2006). Near Death Experience and Spirituality, Zygon Journal of Religion and Science: 41, 393-414. doi: 10.1111/j.1467-9744.2005.00745.x.

Karaca, F., (2000). Ölüm Psikolojisi. Beyan.

Moody, R., (1993). Karşı Tarafin Işı̆̆ı. Çev. Gülengül Giray, Ruh ve madde yayınları.

Ring, K., Valarino, E.E. (2006). Lessons from the Light. Moment Point Press.

Uysal, S (2007). Transpersonel Psikoloji ve Din. Marmara Üniversitesi SBE, Yayınlanmamış yüksek lisans tezi. 